\title{
Low-Density Polyethylene Films Carrying ferula asafoetida Extract for Active Food Packaging: Thermal, Mechanical, Optical, Barrier, and Antifungal Properties
}

\author{
Razieh Niazmand $\mathbb{D}^{1}{ }^{1}$ Bibi Marzieh Razavizadeh, ${ }^{2}$ and Farzaneh Sabbagh ${ }^{3}$ \\ ${ }^{1}$ Department of Food Chemistry, Research Institute of Food Science and Technology, Mashhad, Iran \\ ${ }^{2}$ Department of Food Safety and Quality Control, Research Institute of Food Science and Technology, Mashhad, Iran \\ ${ }^{3}$ Department of Plant Sciences, Faculty of Biological Science, Alzahra University, Tehran, Iran \\ Correspondence should be addressed to Razieh Niazmand; r.niazmand@rifst.ac.ir
}

Received 29 March 2020; Accepted 25 June 2020; Published 13 July 2020

Academic Editor: Iza Radecka

Copyright (c) 2020 Razieh Niazmand et al. This is an open access article distributed under the Creative Commons Attribution License, which permits unrestricted use, distribution, and reproduction in any medium, provided the original work is properly cited.

\begin{abstract}
The physical, thermal, mechanical, optical, microstructural, and barrier properties of low-density polyethylene films (LDPE) containing ferula asafoetida leaf and gum extracts were investigated. Results showed a reduction in elasticity and tensile strength with increasing extract concentration in the polymer matrix. The melting temperature and enthalpy increased with increasing concentration of extracts. The films containing extracts had lower $L *$ and $a *$ and higher $b *$ indices. The films containing leaf extract had more barrier potential to UV than the gum extracts. The oxygen permeability in films containing $5 \%$ of leaf and gum extracts increased by 2.3 and 2.1 times, respectively. The morphology of the active films was similar to bubble swollen islands, which was more pronounced at higher concentrations of gum and leaf extracts. FTIR results confirmed some chemical interactions of ferula extracts with the polymer matrix. At the end of day $14^{\text {th }}$, the growth rate of Aspergillus niger and Saccharomyces cerevisea in the presence of the PE-Gum-5 reduced more than PE-Leaf-5 (3.7 and 2.4 logarithmic cycles, respectively) compared to the first day. Our findings showed that active LDPE films have desire thermo-mechanical and barrier properties for food packaging.
\end{abstract}

\section{Introduction}

The packaging is designed to protect foods from external factors such as temperature, light, and humidity that can lead to destruct them [1]. Besides, packaging preserves its contents against environmental impacts such as odor, microorganisms, shock, dust, vibration, and compressive forces. Exposure to these destructive agents, the shelf life of foods reduces [2].

In the past few years, the development of active food packaging has made it possible to increase their shelf life, while maintaining their nutritional quality and has received much attention. This is mainly achieved through the development of plastic or paper packaging systems that are capable of reducing food oxidation, growth of microorganisms, and migration of pollutants [3]. In this type of packaging, the active agents such as antioxidants, adsorbents, and antimicrobial compounds are incorporated into the matrix of polymer film to gradually release from the film, provide its desired effect, and prevent chemical or microbial spoilage of the food and thus increase its shelf life [4]. The added active agents to the polymer matrix can have a natural or synthetic origin, but nowadays due to the unfavorable effects of synthetic active agents on human health and the environment, the tendency to use molecules and particles with natural origin has increased [5].

To date, many natural active compounds have been used to produce active packaging, for example, López et al. [6] produced tocopherol-releasing polypropylene (PP) films as antioxidants and Rosen-Kligvasser et al. [7] produced linear 
low-density polyethylene (LLDPE) films containing oleic acid monoesters bonded with silica particles as an antifungal additive.

The antimicrobial and antioxidant activities of essential oils and plant extracts have long been known, and there is a strong tendency to use these compounds in food packaging. López-de-Dicastillo [8] developed ethylene vinyl alcohol (EVOH)-based antioxidant films containing 5\% green tea extract. They reported that the color of the films was brown and opaque that the antioxidant compounds of the extract were partially destroyed by the extrusion process. Wattananawinrat et al. [9] developed LDPE/ethylene vinyl acetate (EVA)-based antimicrobial films containing $0.5,2$, and $4 \%$ of essential oil of cloverleaf, basil, and cinnamon bark. Among them, cinnamon essential oil showed the highest antimicrobial effect despite its relatively low shelf life. However, all the films carrying essential oil were able to retain the fresh tomato slices significantly better than the control film (pure LDPE and EVA).

One of the natural and valuable plants that grow in specific areas, such as Iran, is Ferula Asafoetida, which has a potent antimicrobial that is widely used in traditional medicine. The genus Ferula has 30 species in Iran, often distributed in mountains and sometimes in desert areas. Species of this genus are distributed alongside Iran in Anatolia, central Asia, and Afghanistan [10]. In traditional Iranian medicine, its gum extract is used to treat abdominal pain, constipation, diarrhea, and intestinal worms [11]. Its medicinal properties include sedative, antipyretic, digestive antispasmodic, sputum, laxative, analgesic, intestinal worm repellent, disinfectant, and diuretic $[12,13]$.

The Ferula gum contains various compounds such as ferulic acid and its esters, coumarins, sesquiterpene coumarins, monoterpenes, and sulfur compounds such as 2-butyl1-propionyl disulfide, 1-(methyl thio) propyl 1-propenyl disulfide and 3-propyl thio)-2-propenyl disulfides [14-16]. Various researchers have investigated and confirmed the antimicrobial effect of Ferula. Delavar et al. [17] identified 13 compounds in essential oils using GC-MS, most of which contained alpha-pinene (21.3\%), beta-pinene (47.1\%), and 1, 2-dithiolane (18.6\%). The phenol and flavonoid content of the total methanolic extract of Ferula asafoetida aerial parts were reported to be $94.8 \pm 5.9 \mathrm{mg}$ gallic acid/g per extract powder and $90.9 \pm 6.3 \mathrm{mg}$ quercetin/g per extract powder, respectively. The extracts also showed a good inhibitory activity on the nitric oxide $\left(\mathrm{LC}_{50}=270 \pm 3 \mathrm{mg} / \mathrm{ml}\right)$ as well as good chelating ability on iron ( $\mathrm{LC}_{50}=0.57 \pm 0.02 \mathrm{mg} / \mathrm{ml}$ ) [13]. The results of Patil et al. [18] showed that ethyl acetate, ethanol, and methanol extracts of the Ferula had high antimicrobial activity and their minimum inhibitory concentration was 2, 1 , and $1 \mathrm{mg} / \mathrm{ml}$, respectively. The results of Fani et al. [19] and Shrivastava et al. [20] also confirmed the antimicrobial effect of the Ferula.

The addition of active agents to the polymer matrix can affect the mechanical, thermal, optical, and gas barrier properties of the packaging [21]. Therefore, apart from the active properties, the packaging material must have the appropriate thermomechanical and optical properties for food storage and transportation.
To our knowledge so far, the properties of the Ferula have not been used to produce active plastic films for food packaging. Therefore, in this study, different concentrations of hydroalcoholic extract of leaf and gum were added to the LDPE polymer matrix to develop active packaging, and its physical, thermal, mechanical, optical, and microstructural properties were investigated.

\section{Materials and Methods}

2.1. Materials. The ferula asafoetida leaves were collected from Sabzevar in late April and early May. The ferula asafoetida leaves were cleaned and the yellow or damaged leaves were removed, then washed and dried in the shade. The dried leaves were powdered and kept in a cool dry place until running the tests. The gum of the plant was also prepared from Sabzevar. The polyethylene (PE) with 020 grade was purchased from the Iran Petrochemical Company. The medium including potato dextrose agar (PDA) and potato dextrose broth (PDB) were provided from Merck Company. The Aspergillus niger [PTCC 5010 (ATCC 9142)] and the Saccharomyces cerevisiae [PTCC 5051 (ATCC 9080)] were obtained from The Persian Type Culture Collection (PTCC; Tehran, Iran). The solvents and chemicals were provided from Merck and Sigma representations.

2.2. Preparation of Ferula Leaf and Gum Extracts. To isolate the effective compounds of Ferula leaf and gum extracts and to use them in the subsequent stages, the extraction was performed. The hydro-ethanolic (rate of 20 to 80 ) was used for extraction. The ratio of gum or leaf to the solvent was considered as $1: 3$, and the extraction process was performed at ambient temperature for 3 hours. During this time, the mixture was stirred at $500 \mathrm{rpm}$. After this period, the mixture was filtered, and the solvent was removed at $35^{\circ} \mathrm{C}$ to $40^{\circ} \mathrm{C}$. The dried extracts were collected and were kept at $-18^{\circ} \mathrm{C}$ for further analysis.

2.3. Preparation of Active Films. Production of antimicrobial films was done using dry hydro-ethanolic extracts. The mixtures of LDPE granules with the extracts $(1,3$, and 5\%) were prepared. Internal mixing (HAAKE Buchler Product, HBI System 90, US) was used to complete the mixing of the extract with the polymer matrix. The complete mixing was done at $80 \mathrm{rpm}, 110^{\circ} \mathrm{C}$, and $10 \mathrm{~min}$. A rotary mill was used to crush the obtained mixture. Twin-screw extruder (ZSK, Germany) was applied to prepare active LDPE pellets by reactive extrusion of the milled Ferula dry extract-LDPE mixture with an $\mathrm{L} / \mathrm{D}$ ratio of $24 \mathrm{~mm}$, screw diameter of $12 \mathrm{~mm}$, and diameter of $0.25 \mathrm{~cm}$. The extruder was operated with the feeding speed of $50 \mathrm{rpm}$, at $110-150^{\circ} \mathrm{C}$, and the screw speed of $38 \mathrm{rpm}$. Then, the extruded active LDPE resins were quenched at $10^{\circ} \mathrm{C}$ in the cold water and were cut into the pellet shape.

To omit the residual moisture, the Ferula-LDPE pellets were then dried at $80^{\circ} \mathrm{C}$ for $2 \mathrm{~h}$. Then, using a blown extruder (Brabender, Germany) with a screw speed of $47.2 \mathrm{rpm}$, at temperature $110^{\circ} \mathrm{C}$ in the feeding zone, and $200^{\circ} \mathrm{C}$ towards the extrusion die, the dried Ferula-LDPE pellets were 
converted to the films. The prepared films were packed under vacuum and were kept in the fridge for the further experiments. The pure LDPE film was selected as the control sample. The different levels of the compounds were stated as follows: LDPE films containing Ferula 1\%,3\%, and 5\% gum extracts as PE-Gum-1, PE-Gum-3, and PE-Gum-5, and LDPE films containing $1 \%, 3 \%$, and $5 \%$ Ferula leaf extracts as PE-Leaf-1, PE-Leaf-3, and PE-Leaf-5, respectively.

\subsection{Characterization of Active Films}

2.4.1. Thickness. The thickness of films was measured using a digital micrometer (Mitutoyo, coolant proof, Japan) with an accuracy of $0.001 \mathrm{~mm}$. The reported thickness is an average of 20 tests.

2.4.2. Mechanical Properties. The mechanical properties of the films including tensile strength and elongation at rupture were done in six replicates using a tensiometer (TA-XT Plus, Stable Microsystem, UK) according to ASTM-D882-01. For this purpose, the cut strips of the films (dimensions: $7 \mathrm{~cm} \times$ $1 \mathrm{~cm}$ ) were placed between two jaws with a distance $50 \mathrm{~mm}$ and strained at a rate of $1 \mathrm{~mm} / \mathrm{s}$. The obtained data were recorded using a computer. The tensile properties of the film including tensile strength, elongation at rupture, and Young's modulus were calculated from the tensile-strain curves according to data computer using the Exponent software version $6 / 1 / 13$ [22].

2.4.3. Field Emission Scanning Electron Microscopy (FE$S E M)$. The microstructure of active films was studied using an FE-SEM (HITACHI, Model S4160, Japan) with a gold cover and at $25 \mathrm{kV}$ voltage. [23].

2.4.4. Fourier Transform Infrared Spectroscopy (FTIR). The FTIR spectra of the films and the extracts obtained by a spectrophotometer (Avatar, 370 FTIR, Canada) equipped with an ATR diamond probe as 16 scans in the range of 400 to $4000 \mathrm{~cm}^{-1}$ with a resolution of $2 \mathrm{~cm}^{-1}$. The files converted to the numerical data and analysed using FTIR spectrum software [24].

2.4.5. Water Vapor Transmission Rate (WVTR). The water vapor transmission rate (WVTR) of the films using the Water Vapor Permeability Tester (Brugger model, Feinmechanik, Germany) and according to ASTM E398 was done. The films were cut into the circles and were placed in the device chamber. Before the experiments, the parameters were adjusted in this way: Steady-state, effective surface of $78.4 \mathrm{~cm}^{2}$, the temperature of $25^{\circ} \mathrm{C}$, passing and dry side relative humidity of $100 \%$ and $10 \%$. Results were reported in $\mathrm{g} / \mathrm{m}^{2}$ day.

2.4.6. Oxygen Permeability (OP). The oxygen permeation through the films was measured using the Gas Permeability Tester (Brugger, model Feinmechanik, Germany). The films were cut circularly with an effective area of $78.4 \mathrm{~cm}^{2}$ and were placed in the gas distribution cell of the device. Before the experiments, the parameters were set as follows: continuous mode, the temperature of $25^{\circ} \mathrm{C}$, relative humidity of $50 \%$. Results were reported in $\mathrm{cm}^{3} / \mathrm{m}^{2}$ day [25].
2.4.7. Thermal Properties. To evaluate the thermal degradation and the mass reduction of the films and extracts as a function of temperature, thermogravimetric analysis (TGA) was performed according to ASTM E1131-14 and Saeidy et al. [26] method with a slight modification using TGA apparatus (Mettler Toledo, Model TGA, Swiss). The samples heated in the range of $5-600^{\circ} \mathrm{C}$ with a rate of $10^{\circ} \mathrm{C} / \mathrm{min}$ under nitrogen atmosphere.

The thermal properties of the films and extracts were studied using a Differential Scanning Calorimeter (DSC), (Mettler Toledo, Model DSCI, Switzerland) through heating modes (Martínez-Camacho, et al., 2013). At the ambient conditions, $25^{\circ} \mathrm{C}$ and $30 \%$ air humidity, about $15 \mathrm{mg}$ of the sample was carefully weighed in a sealed aluminum pan, then changed from 5 to $500^{\circ} \mathrm{C}$, with an increased rate of temperature $10^{\circ} \mathrm{C} / \mathrm{min}$ and was heated under a constant flow of dry nitrogen.

2.4.8. Color and Optical Properties. The color parameters including $L$ (brightness), $a$ (red/green), and $b$ (yellow/blue) were measured by the Hunter lab colorimeter (Model 45.0, CX2547, USA). The total color difference $(\Delta \mathrm{E})$ was obtained using the following equation:

$$
\begin{aligned}
\Delta E= & \left(\left(\mathrm{L}_{\text {Sample }}-\mathrm{L}_{\mathrm{LDPE}}\right)^{2}+\left(\mathrm{b}_{\text {Sample }}-\mathrm{b}_{\mathrm{LDPE}}\right)^{2}\right. \\
& \left.+\left(\mathrm{a}_{\text {Sample }}-\mathrm{a}_{\mathrm{LDPE}}\right)^{2}\right)^{1 / 2}
\end{aligned}
$$

The rate of light transmittance in the ultraviolet area $(280 \mathrm{~nm}$ wavelength) and visible area $(600 \mathrm{~nm})$ was measured using a spectrophotometer (HACH, DR500, USA). The transparency value (TV) was calculated using equation (2):

$$
\mathrm{TV}=\left(-\log \mathrm{T}_{600}\right) / \mathrm{x}
$$

The T600 is the light transmittance of $600 \mathrm{~nm}$ and $x$ is the thickness of the film [27].

2.4.9. Antimicrobial Activity. The antimicrobial activity of the PE-Leaf-5 and PE-Gum-5 films versus Saccharomyces cerevisiae and Aspergillus niger was evaluated based on the Mulla et al. [27] method with a little modification. For this purpose, the films with $2 \mathrm{~cm} \times 1.5 \mathrm{~cm}$ slices were immersed into a bottle with a screw cap containing $10 \mathrm{ml}$ of liquid culture medium. To evaluate the antimicrobial activity of $S$. cerevisiae and A. niger, $0.1 \mathrm{ml}$ of each microorganism with a concentration of $10^{5} \mathrm{cfu} / \mathrm{ml}$ was inoculated to the PDB culture mediums. The cap of bottles was tightly screwed, and they were placed in the shaker $(250 \mathrm{rpm})$ at $25^{\circ} \mathrm{C}$. Then, at a specified interval, $1 \mathrm{ml}$ of it, was removed and diluted, respectively. Then, it was spread out on the PDA and was incubated at $25^{\circ} \mathrm{C}$. After $24-48$ hours incubation for Saccharomyces and 5-7 days for Aspergillus, colony-forming units were read, and the results were reported as a $\log \mathrm{cfu} / \mathrm{ml}$.

2.5. Statistical Analysis. In this study, the experiments were performed in triplicate. The analysis of the data was done using the two-way ANOVA, based on a completely randomized simple design and using Minitab software version 16.2.4. 
The comparisons of means were made using Tukey's test at a 95\% confidence level $(P<0.05)$. The curves were drawn using the excel software version 2010.

\section{Results and Discussion}

3.1. Thickness of Films. The Table 1 shows the thickness of PE-Leaf and PE-Gum films compared to the pure LDPE. The results showed that there was a significant difference between the films containing $5 \%$ of the gum extract (PEGum-5) and the control film $(P<0.05)$, while the other films did not show a significant difference with the pure LDPE film $(P>0.05)$. As the leaf extract concentration increased, the thickness of the films decreased slightly, while that of the gum extract increased, the thickness of films increased but none of these changes were significant $(P>0.05)$. Looks like the leaf extract is capable of filling the pores in the polymer matrix, thus limiting the increase in thickness in the PELeaf films, while some of the gum extract compounds cannot fit into the polymer matrix structure. This increases the volume of the film and therefore its thickness. Mulla et al. [27] reported that the thickness of LLDPE films coated with clove essential oil was more than pure LLDPE films.

3.2. Mechanical Properties. The mechanical and tensile properties of applied films for food packaging to maintain the integrity of the product are very important. The tensile properties of the films not only depend on the extrusion conditions, such as the number of screws, temperature and the rotation speed, the residence time in the device and the molding, injection, or blowing parameters, but also depend on the type of the polymer and the additives to the matrix [28]. Since the present study has considered the conditions of the film production by fixed extruders, therefore, the only parameter affecting the properties of the produced films is the change in the percentage of the extract blended with the polymer.

The elongation at the rupture of PE-Leaf and PE-Gum films compared to the control film has been shown in Table 2. The results showed that the increase in the concentration of the leaf and gum extracts in the polymer matrix from 1 to $5 \%$ led to a significant decrease in the elongation at the rupture, compared to the pure LDPE $(P<0.05)$. However, there were no significant differences between the elongation of the films containing different amounts of extract. This trend has also been reported by the other researchers $[29,30]$. They attributed this process to the poor miscibility of the added compound with the LDPE or variation in its crystallinity that caused to its low mobility.

The results of the tensile strength test also showed that only PE-Gum-5 film was different from the control and the active films (except PE-Leaf-1 film), and its tensile strength was significantly lower than them $(P<0.05)$. Remedio et al. [31] showed that the tensile strength of the chitosan films containing $10 \mathrm{mg}$ polysorbate and nisin decreased $45.5 \%$ and $19.4 \%$, respectively, comparing to the pure chitosan film, indicating a decrease in the chitosan resistance. The reason for this was attributed to the interactions of the antimicrobial compounds that could readily penetrate in the film matrix,
TABLe 1: Thickness (mean \pm SD) of control and active films.

\begin{tabular}{lcc}
\hline Sample film & Concentration (\%) & Thickness $(\mathrm{mm})$ \\
\hline LDPE & 0 & $0.0570 \pm 0.0026^{\mathrm{B}}$ \\
\hline \multirow{3}{*}{ PE-Leaf } & 1 & $0.0685 \pm 0.0022^{\mathrm{AB}}$ \\
& 3 & $0.0588 \pm 0.0013^{\mathrm{B}}$ \\
& 5 & $0.0568 \pm 0.0014^{\mathrm{B}}$ \\
\multirow{3}{*}{ PE-Gum } & 1 & $0.0497 \pm 0.0021^{\mathrm{B}}$ \\
& 3 & $0.0637 \pm 0.0107^{\mathrm{AB}}$ \\
& 5 & $0.0843 \pm 0.0180^{\mathrm{A}}$ \\
\hline
\end{tabular}

Nonsimilar letters indicate a significant difference according to Tukey's test $(P<0.05)$.

resulting in the production of a film with less tensile strength and greater flexibility.

The results showed that the PE-Gum-3 and PE-Gum-5 films had a significant difference in Young's modulus $(P<0.05)$. The findings of $\mathrm{Ma}$ et al. [32] also indicated that the tensile strength of EVOH of the antimicrobial films containing cinnamaldehyde is not changed compared to the pure film. They explained that the small cinnamaldehyde molecules filled the EVOH macromolecules matrix, which did not change the tensile strength. Liang and Wang's [33] results showed that in the antimicrobial soy protein isolate films containing higher than 15\% Cortex Phellodendron extract, tensile strength, and elongation at the rupture, decreased that were attributed to the molecular interactions between the extract, soy protein, and glycerol.

3.3. FTIR. As shown in Figure 1, the FTIR results of the leaf and gum extracts and comparing of the films containing them with the pure polyethylene films are presented. The FTIR spectra bands revealed that the pure LDPE film in the band at $2913-2846 \mathrm{~cm}^{-1}$ (C-H stretch), $1463-1470 \mathrm{~cm}^{-1}$ (bending $\mathrm{CH}_{3}$ ), 1376 and $717 \mathrm{~cm}^{-1}$ (skeletal vibrations) has prominent peaks consistent with the results of Mulla et al. [27].

FTIR spectra of the gum extract showed a broadspectrum at 3563 to $3329 \mathrm{~cm}^{-1}$ which is attributed to the O$\mathrm{H}$ stretch and may indicate phenolic compounds, water, or alcohol residues. Also, the prominent bands at 2913$2970 \mathrm{~cm}^{-1}$ (O-H stretch (indicating Hydroxyl or carboxyl groups) or $\mathrm{C}-\mathrm{H}$ tensile vibrations $), 1617.7 \mathrm{~cm}^{-1} \quad(\mathrm{C}=\mathrm{C}$ stretch), $1461-1209 \mathrm{~cm}^{-1}$ ( $\mathrm{S}=\mathrm{O}$ stretch), $1128.9-1069.4 \mathrm{~cm}^{-1}$ (C-O stretch), 682.8-990.2 $\mathrm{cm}^{-1}$ ( $\mathrm{C}=\mathrm{C}$ bending), and 471.4$583.9 \mathrm{~cm}^{-1}$ were observed in the gum extract. Saeidy et al. [26] also revealed the prominent bands at 3287, 2924, $1598.1,1200-820$, and $820-400 \mathrm{~cm}^{-1}$ in the Ferula gum extract that is attributed to the $\mathrm{O}-\mathrm{H}$ vibration of polysaccharides or bound water, stretch vibration of $\mathrm{C}-\mathrm{H}$, asymmetric stretching of residual carboxyl groups of the uranic acid, gum fingerprint area, and the symmetrical or asymmetric vibrations of $\mathrm{C}-\mathrm{C}-\mathrm{O}$ and $\mathrm{C}-\mathrm{O}-\mathrm{C}$, respectively.

The investigation of the FTIR spectra bands of PE-Gum5 indicated the appearance of bands at 3292.4, 1047.5, and $994.4 \mathrm{~cm}^{-1}$ comparing to the pure LDPE film. Also, it was observed that the peaks 2913.7, 2845.5, 1462.2-1470.6, $1367.56-1376.6$, and $717.5-733.3 \mathrm{~cm}^{-1}$ were shifted to 2913 , 
TABLE 2: Mechanical properties (mean \pm SD) of control and active films.

\begin{tabular}{lcccc}
\hline Film & Concentration (\%) & Elongation at rupture point (\%) & Tensile strength (m.Pa) & Young's modulus (m.Pa) \\
\hline LDPE & 0 & $376.70 \pm 37.76^{\mathrm{A}}$ & $10.29 \pm 0.62^{\mathrm{A}}$ & $1.71 \pm 0.06^{\mathrm{AB}}$ \\
\hline \multirow{3}{*}{ PE-Leaf } & 1 & $135.44 \pm 30.90^{\mathrm{B}}$ & $8.64 \pm 0.64^{\mathrm{AB}}$ & $1.47 \pm 0.12^{\mathrm{AB}}$ \\
& 3 & $131.90 \pm 47.34^{\mathrm{B}}$ & $9.12 \pm 1.06^{\mathrm{A}}$ & $1.43 \pm 0.25^{\mathrm{AB}}$ \\
\hline & 5 & $119.82 \pm 12.13^{\mathrm{B}}$ & $9.79 \pm 1.46^{\mathrm{A}}$ & $1.57 \pm 0.46^{\mathrm{AB}}$ \\
PE-Gum & 1 & $115.18 \pm 18.61^{\mathrm{B}}$ & $9.80 \pm 0.22^{\mathrm{A}}$ & $1.60 \pm 0.10^{\mathrm{AB}}$ \\
& 3 & $108.19 \pm 30.78^{\mathrm{B}}$ & $9.70 \pm 0.96^{\mathrm{A}}$ & $1.95 \pm 0.18^{\mathrm{A}}$ \\
\hline
\end{tabular}

Nonsimilar letters in each column indicate a significant difference according to Tukey's test $(P<0.05)$.

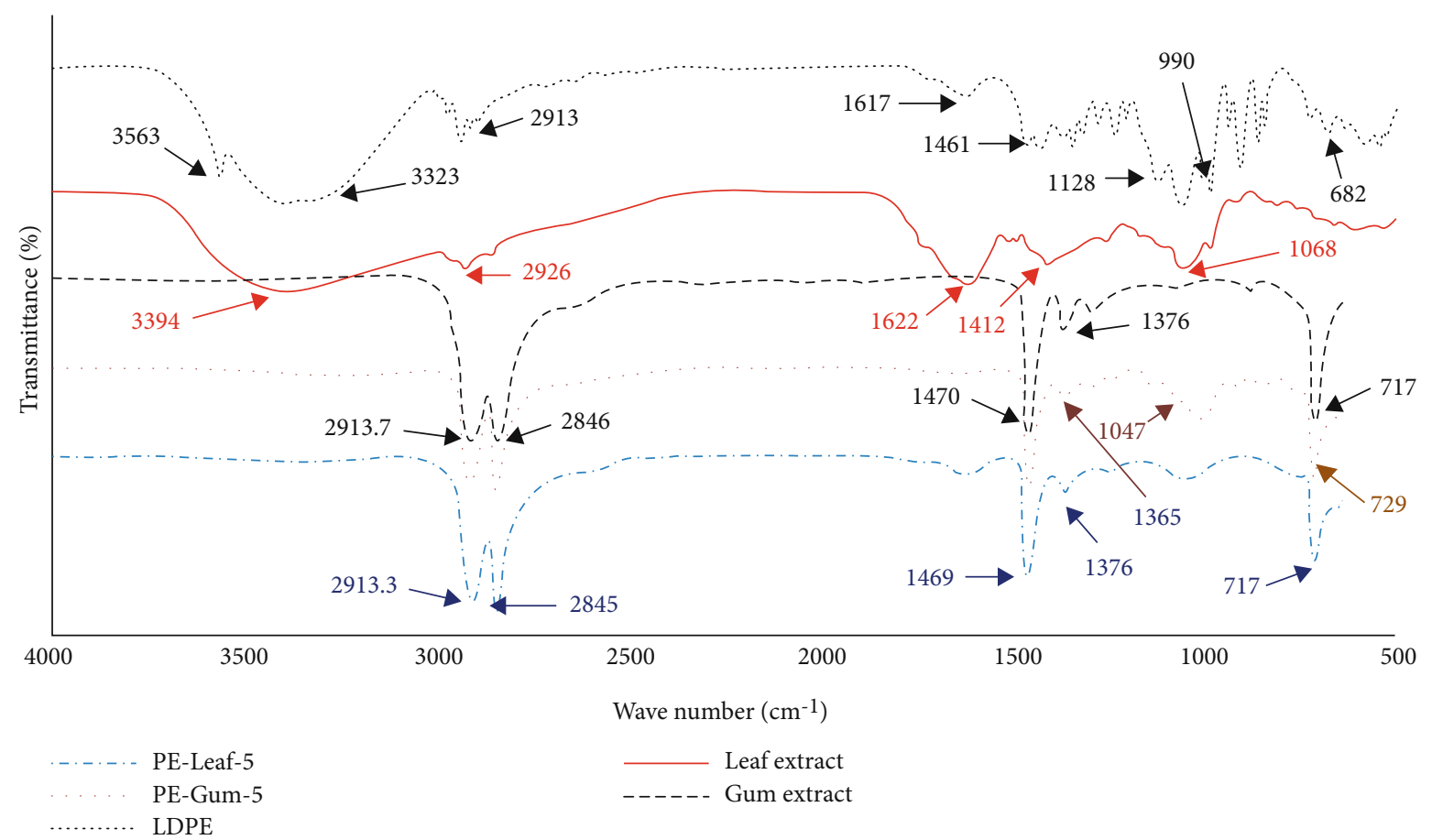

Figure 1: FTIR spectrum of leaf extract, gum extract, and active films containing 5\% extract in comparison with pure polyethylene film.

2844.5, 1461.4-1470, 1365.4-1375.3, and 717.1-729.4 $\mathrm{cm}^{-1}$, respectively.

The FTIR spectra of the leaf extract showed a broad and strong spectrum at $3394.9 \mathrm{~cm}^{-1}$ which indicated the $\mathrm{O}-\mathrm{H}$ stretch and the presence of large amounts of hydroxyl group compounds in the extract. Also, prominent peaks at $2926.4 \mathrm{~cm}^{-1}$ (C-H tensile vibrations), $1622.9 \mathrm{~cm}^{-1} \quad(\mathrm{C}=\mathrm{C}$ stretch), $1412.8-1262.2 \mathrm{~cm}^{-1}$ ( $\mathrm{S}=\mathrm{O}$ stretch), $1068.5-1049.7 \mathrm{~cm}^{-1}$ (C-O stretch), 665.6-555.3 $\mathrm{cm}^{-1}$ ( $\mathrm{C}=\mathrm{C}$ bending), and $471.4-$ $583.9 \mathrm{~cm}^{-1}$ were observed in the leaf extract. The FTIR spectrum of PE-Leaf-5 indicated that the prominent peaks of pure LDPE film can be seen in the mentioned film with some displacement so that peaks at 2913.7, 2845.5, 1470.6-1462.2, $1376.6-1367.6$, and $733.3-717.5 \mathrm{~cm}^{-1}$ slightly shifted to 2913.3, 2845.1, 1469-1461.5, 1376.6-1367, and 731.4-717.2, respectively. Also, the appearance of the new spectra at $3364.7,1605.5$, and $1078.9-1043.3 \mathrm{~cm}^{-1}$ indicated the presence of leaf extract in the polyethylene polymer matrix.
3.4. Microstructure. The images obtained from the pure and active polyethylene films are shown in Figure 2. The pure LDPE film had a uniform and homogeneous surface morphology, while the addition of leaf or gum extract resulted in the physical changes in the LDPE matrix. The gum extract was observed as the spherical and bright spots (white) in the LDPE matrix, whereas in the films containing $1 \%$ leaf extract, these spots were less observed, but at 5\% concentration, they were more visible and less spherical. In the active films, the swollen island-like regions and bubbles were observed which is more pronounced at the higher concentrations of gum and leaf extract. It is observed that the increasing in the concentration of extracts, especially in the films containing gum extract, causes expanding the swelling points and widening of the swelling conditions. This can affect the permeability and tensile strength of the films and causes the breakdown of polymer structure. Chen et al. [34] also confirmed that the addition of $1 \%$ clove oil to the EVOH films caused the 


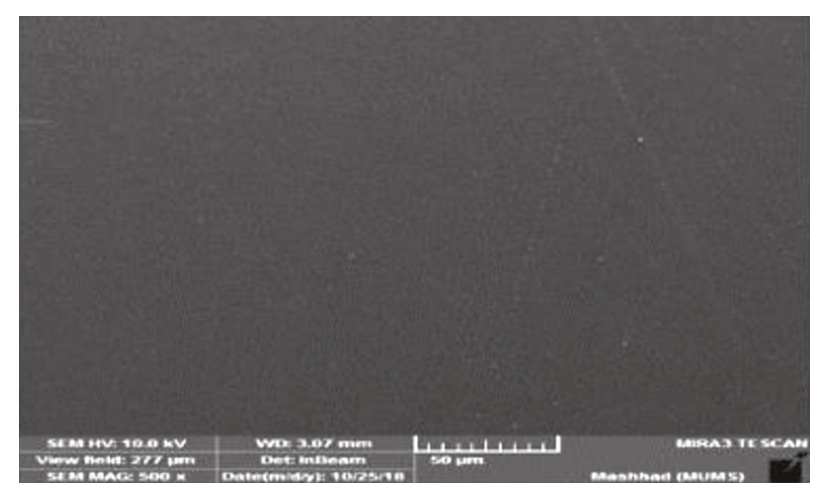

(a)

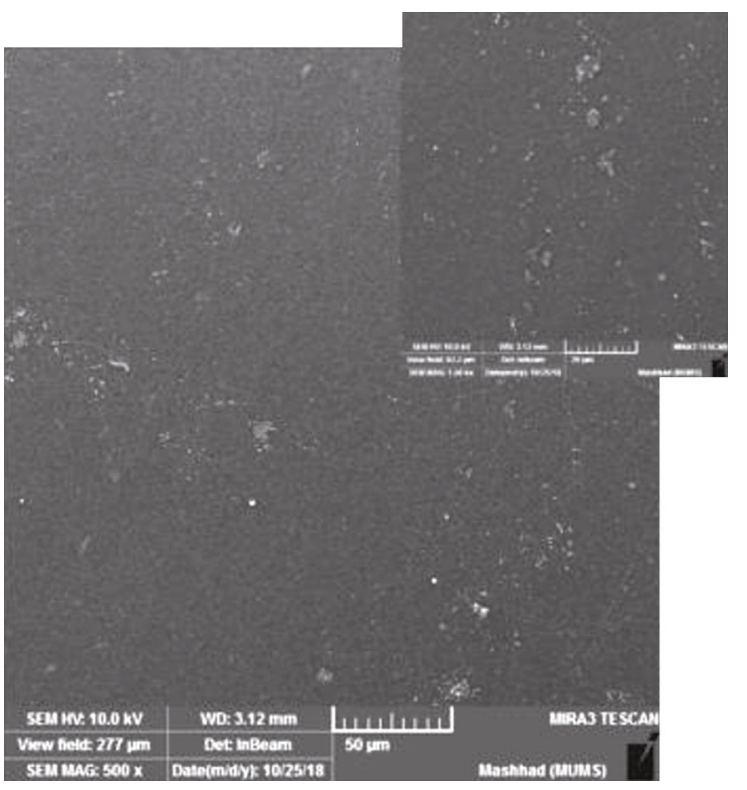

(c)

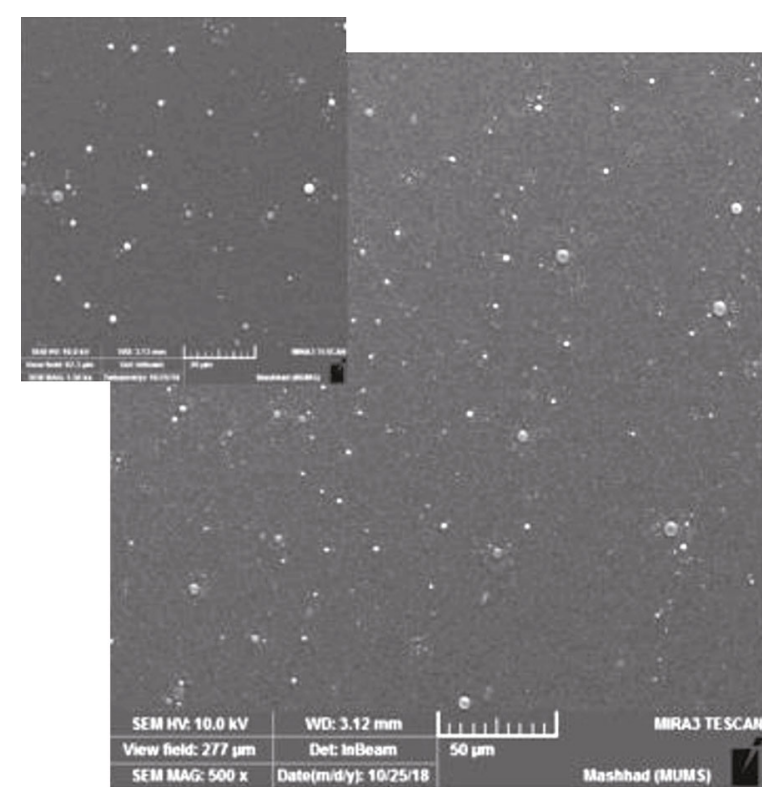

(b)

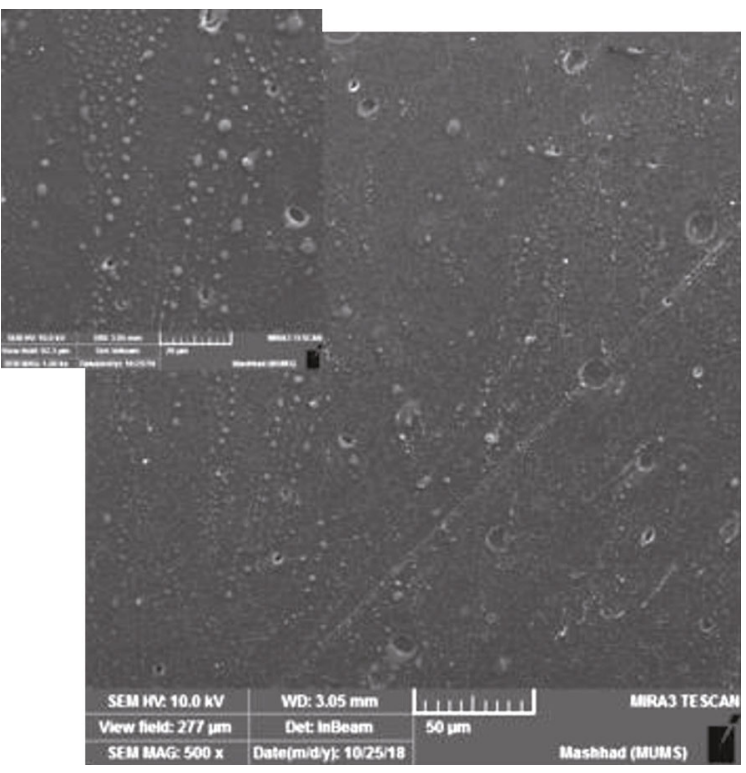

(d)

Figure 2: Continued. 


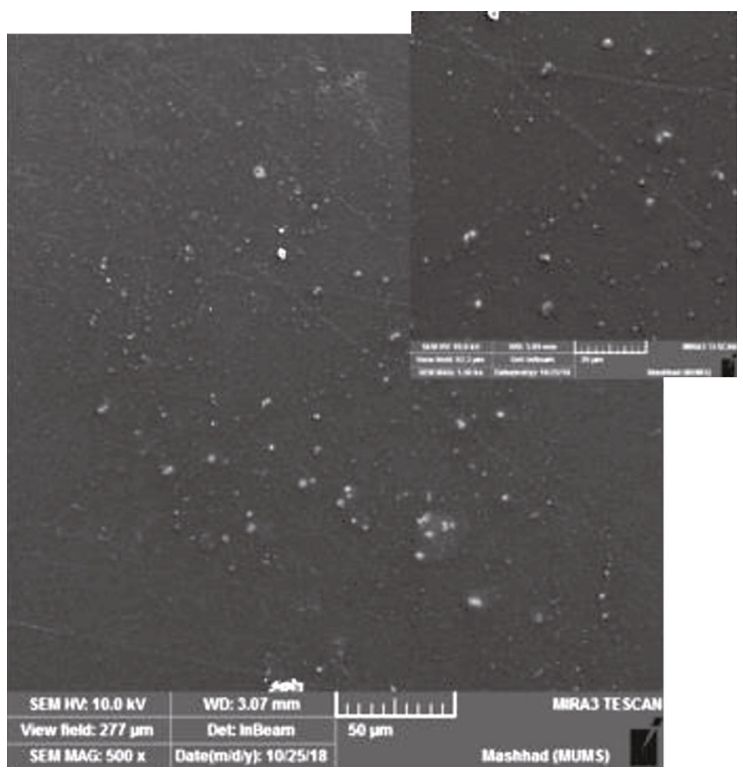

(e)

Figure 2: SEM surface images of films with magnification of 500 and 1500 (thumbnails): (a) LDPE film; (b) PE-Gum-1; (c) PE-Leaf-1; (d) PEGum-5 (e); PE-Leaf-5.

TABLE 3: Color parameters (mean \pm SD) of control and active films.

\begin{tabular}{lccccc}
\hline Film sample & Concentration (\%) & $\mathrm{L} *$ & $\mathrm{a} *$ & $\mathrm{~b} *$ & $\Delta \mathrm{E}$ \\
\hline LDPE & 0 & $93.93 \pm 0.87^{\mathrm{A}}$ & $4.02 \pm 0.20^{\mathrm{A}}$ & $-6.57 \pm 0.31^{\mathrm{G}}$ & - \\
\hline \multirow{3}{*}{ PE-Leaf } & 1 & $88.78 \pm 0.30^{\mathrm{D}}$ & $3.64 \pm 0.12^{\mathrm{B}}$ & $1.73 \pm 0.26^{\mathrm{C}}$ & $9.77 \pm 0.30^{\mathrm{C}}$ \\
& 3 & $86.21 \pm 0.19^{\mathrm{E}}$ & $2.65 \pm 0.16^{\mathrm{D}}$ & $7.53 \pm 0.32^{\mathrm{B}}$ & $16.14 \pm 0.08^{\mathrm{B}}$ \\
& 5 & $81.90 \pm 1.09^{\mathrm{F}}$ & $1.72 \pm 0.11^{\mathrm{E}}$ & $14.12 \pm 0.22^{\mathrm{A}}$ & $24.04 \pm 0.13^{\mathrm{A}}$ \\
\multirow{3}{*}{ PE-Gum } & 1 & $93.58 \pm 0.96^{\mathrm{A}}$ & $4.21 \pm 0.12^{\mathrm{A}}$ & $-5.82 \pm 0.22^{\mathrm{F}}$ & $0.87 \pm 0.16^{\mathrm{F}}$ \\
& 3 & $92.63 \pm 1.01^{\mathrm{B}}$ & $3.51 \pm 0.14^{\mathrm{BC}}$ & $-3.35 \pm 0.07^{\mathrm{E}}$ & $3.51 \pm 0.01^{\mathrm{E}}$ \\
& 5 & $91.78 \pm 0.74^{\mathrm{C}}$ & $3.30 \pm 0.10^{\mathrm{C}}$ & $-1.65 \pm 0.08^{\mathrm{D}}$ & $5.42 \pm 0.17^{\mathrm{D}}$ \\
\hline
\end{tabular}

Nonsimilar letters in each column indicate a significant difference according to Tukey's test $(P<0.05)$.

surface roughness but the oil droplets were not apparent, while the increasing in the oil concentration up to $9 \%$ resulted in the surface roughness of the films and oil droplets. It was observed on the surface and with increasing the concentrations, the size of these droplets increased.

The results of other researchers also confirmed the decrease in the surface uniformity and an increase in the pores, which are the results of the addition of an additive to the polymer matrix [35-37].

3.5. Color and Optical Properties. The color parameters of the PE-Gum and PE-Leaf films are shown in Table 3. The results showed that in the films containing leaf and gum extract $L *$ index (except $1 \%$ concentration of gum extract) decreased significantly $(P<0.05)$. The increasing in the concentration of the extract from 1 to $5 \%$ was associated with a further decrease of $L *$ index. The decrease in the $L *$ index indicated a decrease in the brightness of the films. The darker films can be an advantage for the storage of light-sensitive foods. The results also showed that the addition of the leaf extract to the polyethylene polymer matrix reduced $a *$ parameter significantly which presents increasing in the greenness of the films. Given the greenness of the leaf extract, this result was not unexpected. In the PE-Gum films, a tendency to the greenness was also observed, but $a *$ index showed a significant difference in the PE-Gum-3 and PE-Gum-5 with the control $(P<0.05)$. Generally, the $b *$ index in the films containing leaf extract tended to be yellowness and with increasing the amount of added extract to the polymer matrix, the $b$ $*$ index (yellowness) increased $(P<0.05)$. The same was true for the films containing the gum extract, but the amount of yellowness was lower. The results showed that with increasing the amount of extract of gum or leaf in the polymer matrix, the total color difference $(\Delta \mathrm{E})$ with the control film was significantly increased $(P<0.05)$ especially in the films containing leaf extract. Maryam Adilah et al. [38] explained that in the isolated soybean protein and fish gelatin films, by increasing the concentration of mango kernel extract, the $L *$ index decreased $13 \%$ and $8 \%$, respectively, indicating darkening of the film due to the light diffusion and reflection 
TABLE 4: Optical parameters (mean $\pm \mathrm{SD})$ of control and active films.

\begin{tabular}{lcccc}
\hline Film sample & Concentration (\%) & Light transmittance at 280 nm & Light transmittance at 600 nm & Transparency value \\
\hline LDPE & 0 & $52.37 \pm 5.66^{\mathrm{AB}}$ & $79.50 \pm 6.07^{\mathrm{A}}$ & $1.77 \pm 0.54^{\mathrm{AB}}$ \\
\hline \multirow{3}{*}{ PE-Leaf } & 1 & $28.47 \pm 6.17^{\mathrm{D}}$ & $84.20 \pm 0.80^{\mathrm{A}}$ & $1.01 \pm 0.06^{\mathrm{B}}$ \\
& 3 & $13.87 \pm 0.87^{\mathrm{E}}$ & $81.57 \pm 0.49^{\mathrm{A}}$ & $1.53 \pm 0.05^{\mathrm{AB}}$ \\
\hline & 5 & $5.67 \pm 1.86^{\mathrm{E}}$ & $77.80 \pm 0.95^{\mathrm{A}}$ & $1.95 \pm 0.10^{\mathrm{A}}$ \\
PE-Gum & 1 & $63.67 \pm 2.75^{\mathrm{A}}$ & $84.67 \pm 1.63^{\mathrm{A}}$ & $0.98 \pm 0.11^{\mathrm{B}}$ \\
& 3 & $46.60 \pm 3.90^{\mathrm{BC}}$ & $81.83 \pm 1.86^{\mathrm{A}}$ & $1.50 \pm 0.17^{\mathrm{AB}}$ \\
\hline
\end{tabular}

Nonsimilar letters in each column indicate a significant difference according to Tukey's test $(P<0.05)$.

TABLE 5: Oxygen permeability and water vapor transmission rate of control and active films.

\begin{tabular}{lccc}
\hline Film & Concentration (\%) & Oxygen permeability $\left(\mathrm{cm}^{3} / \mathrm{m}^{2}\right.$ day bar $)$ & Water vapor transmission rate $\left(\mathrm{g} / \mathrm{m}^{2}\right.$ day) \\
\hline LDPE & 0 & 1550 & 0.350 \\
\hline \multirow{3}{*}{ PE-Leaf } & 1 & 1010 & 0.327 \\
& 3 & 1590 & 0.318 \\
\hline \multirow{4}{*}{ PE-Gum } & 5 & 3630 & 0.535 \\
& 1 & 1830 & 0.361 \\
& 3 & 2390 & 0.375 \\
\hline
\end{tabular}

by the extract droplets. By increasing the concentration of the mango kernel extract, $a *$ and $b *$ indices tended to be more red and yellow.

Table 4 shows the amount of light passing through the visible and ultraviolet regions (wavelengths 600 and $280 \mathrm{~nm}$ ), respectively. Analysis of variance showed that there was no significant difference between the light transmittance of control and active polyethylene films, $(P>0.05)$, and all the films had more than $77 \%$ light transmittance at $600 \mathrm{~nm}$. The rate of the light passing at a wavelength of $280 \mathrm{~nm}$ expresses the barrier potential against the UV radiation. Results showed that light transmittance at $280 \mathrm{~nm}$ was lower in all the films, and there was a significant difference between them $(P<0.05)$. The light transmittance at $280 \mathrm{~nm}$ was significantly lower in the films containing leaf extract than the control film $(P<0.05)$ and decreased with increasing in the extract concentration, indicating a greater barrier against UV. In the terms of the light transmittance in the UV area, there was no significant difference between the films containing 1 and 3\% concentration of gum extract and control film, whereas by increasing the concentration of gum extract to $5 \%$, the barrier to the UV was significantly increased. The high barrier to the $\mathrm{UV}$ for PE-Leaf films is related to the presence of pigments and UV-absorbents such as phenolic and flavonoid compounds. No significant difference was observed between the transparency value of the active films at the concentrations of 1 and $3 \%$ and the control film, but in the films containing $5 \%$ concentration of leaf and gum extracts, the transparency value increased. This indicates a decrease in the amount of light transmittance at $600 \mathrm{~nm}$ and an increase in the turbidity. Liang and Wang [33] in considering the light transmit- tance at the wavelengths 200 to 300 of soy protein isolate antimicrobial films containing cortex Phellodendron extract showed that the light transmittance was zero, while at the wavelength of 300 to 400 light transmittances exist, but very low, indicating the more barrier properties of films against the UV radiation.

3.6. Water Vapor Transmission Rate (WVTR). The WVTR of the active films in comparison with the pure polyethylene is given in Table 5. The results showed that the addition of leaf extract to the LDPE matrix at $1 \%$ and $3 \%$ was associated with a slight decrease in the WVTR compared to the control, which could be due to the hydrophobic interaction between the polymer and the extract, the appropriate blend of leaf extract in the polymer matrix and the filling of the matrix vacancies with the molecules present in the extract. Unlike the leaf extract, the addition of gum extract to the LDPE polymer matrix was associated with a slight increase in the WVTR which may be due to the existence of more hydrophilic compounds such as polysaccharides in the gum extract. As the SEM images showed, at the low concentrations of the extracts, the polymer matrix did not change significantly, which can confirm that there is no disruption of the original film structure, and consequently, there is no significant change in the WVTR. The ratio of the hydrophobicity of the film components is an important factor in the transmitting water molecules through the film; the increase of hydrophobicity reduces the water transmission. By increasing the concentration of the leaf and gum extracts to $5 \%$, the WVTR was significantly increased to $34.58 \%$ and $22.29 \%$, respectively. As the concentration of the extract 


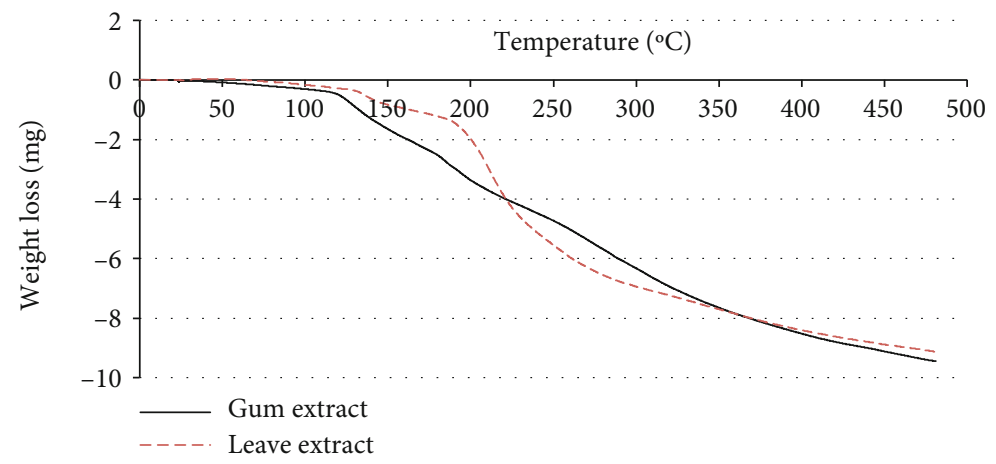

Figure 3: TGA thermograms of leaf and gum extracts.

increased, the structure of the regular and integrated LDPE matrix changed. The disruption of the structure creates holes and grooves for water vapor to pass through, leading to an increase in the WVTR. It was reported that the addition of 5\% mango kernel extract to the fish gelatin resulted in a $17 \%$ increase in WVP. The gelatin films have a regular structure and therefore the addition of mango kernel extract disrupts the regular structure and creates holes and grooves for the water passage that lead to increased WVP [38]. Jafarzadeh et al. [39] showed that WVP in the films based on semolina flour and containing different ratio $(1: 4,3: 2,0: 5$, and $5: 0)$ of $\mathrm{ZnO}$ and kaolin decreased by 43 to $53 \%$ which was attributed to the increase of the winding paths for gas passage in the nanocomposite films due to the impermeability of the added nanoparticles.

To preserve the foods better and to increase their shelf life, it is necessary to decrease the water vapor permeability through the packaging. The factors affecting the WVP films include uniformity and the distribution of added material in the polymer matrix, the formation of cavity or pores, ambient humidity, temperature, type, and concentration of applied softener [38] WVP may decrease or increase.

3.7. Oxygen Permeability (OP). The results of oxygen permeation (Table 5) showed that compared to the control, with increasing the concentration of leaf or gum extract in the LDPE matrix, the OP increased (except for $1 \%$ leaf extract concentration). In the films containing $1 \%$ and $3 \%$ gum extract, the increase of OP was more significant than the leaf extract. The OP in the PE-Leaf-5 and PE-Gum-5 increased to 2.3 and 2.1 times, respectively. The disruption of the integrated structure of the LDPE polymer resulting in the creation of pathways, cavities, and grooves in the matrix, facilitated the passage of oxygen gas and led to an increase in OP. These results are consistent with the images obtained from SEM. Chen et al. [34] also reported that the oxygen transmittance rate of the film increased by increasing in the concentration of clove oil in the PVA film due to the heterogeneous and disorganized structure, caused by the addition of clove oil.

3.8. Thermal Properties. The thermal mass measurement is a simple method based on the determination of sample weight during heating. This method provided a valuable data when the material decomposes during heating or reacts with the surrounding gas in the environment [40]. The TGA diagrams of leaf and gum extracts are shown in Figure 3. The weight loss of polyethylene starts at about $400^{\circ} \mathrm{C}$. Whereas, the degradation of leaf and gum extract started slowly at about $100^{\circ}$ $\mathrm{C}$, and the weight loss of leaf and gum extract at $200^{\circ} \mathrm{C}$ was $13.95 \%$ and $23.5 \%$, respectively.

The DTA curves of LDPE, PE-Leaf-5, and PE-Gum-5 films are shown in Figure 4. The thermal gravimetric results of the PE-Leaf-5 and PE-Gum-5 films indicated two-step degradation in these films that the first step of degradation was similar to that of the leaf and gum extracts at the temperature of $100^{\circ} \mathrm{C}$, and the main step of degradation of both films was similar to polyethylene at a temperature of about $400^{\circ} \mathrm{C}$. There was no significant difference in the thermal behavior of the active films. These observations suggest that the blending of the extract of gum and leaf with polyethylene is well done. Liang and Wang [33] stated that in the soy protein isolate films containing Cortex Phellodendron extract weight loss at the temperature of $30-120^{\circ} \mathrm{C}$ and $300-400^{\circ} \mathrm{C}$ related to the water loss and the degradation of soybean proteins, respectively. According to the researchers, the addition of the extract did not cause a significant change in the TGA but increased the initial degradation temperature from 75.13 to $87.51^{\circ} \mathrm{C}$ which was due to the molecular interaction. The results of Arrieta et al. [41] indicated that the catechin increased the temperature of the onset of degradation and delayed the starting point of the thermal decomposition in a mixture of poly acetic acid films with catechin-containing polyhydroxybutyrate. The changes in the thermal behavior of the leaf and gum extract and the polyethylene film based on the graphs obtained from the DSC are shown in Figure 5. The two exothermic and endothermic peaks were observed in the extracts, whereas polyethylene film represents just an endothermic peak. As can be seen, the process of heating the leaf and the gum extracts was exothermic in the temperature range of 38 to $161^{\circ} \mathrm{C}$ and 61 to $161^{\circ} \mathrm{C}$, respectively.

This process was exothermic for the PE-Leaf and PEGum (Figure 6) in the temperature range of 70 to $170^{\circ} \mathrm{C}$. The melting temperature and the enthalpy of the active films compared to control are shown in Table 6 . The first peak on the thermograms of the leaf and gum extract was observed in the temperature range of 100 to $112^{\circ} \mathrm{C}$. The same result was seen in the films containing them with a slight increase. But 


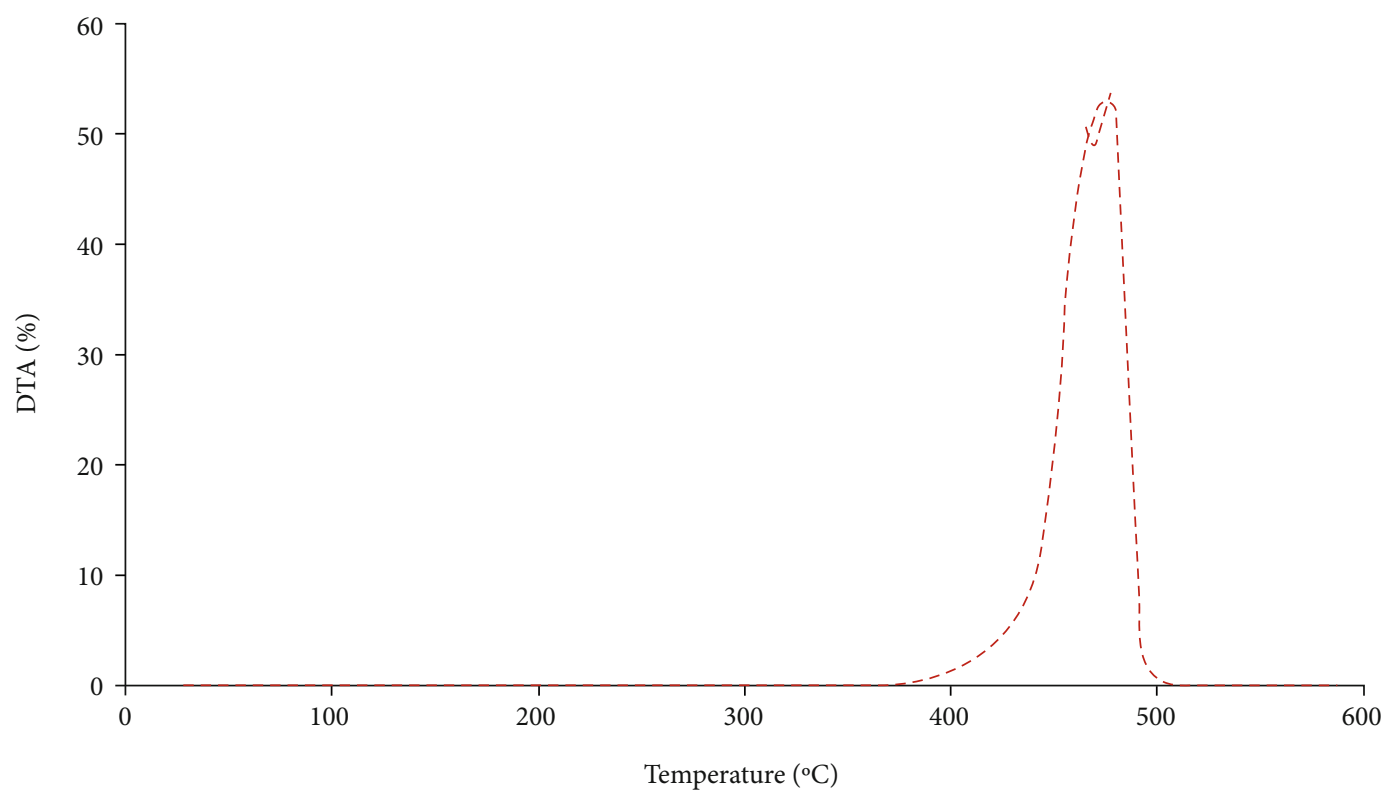

(a)

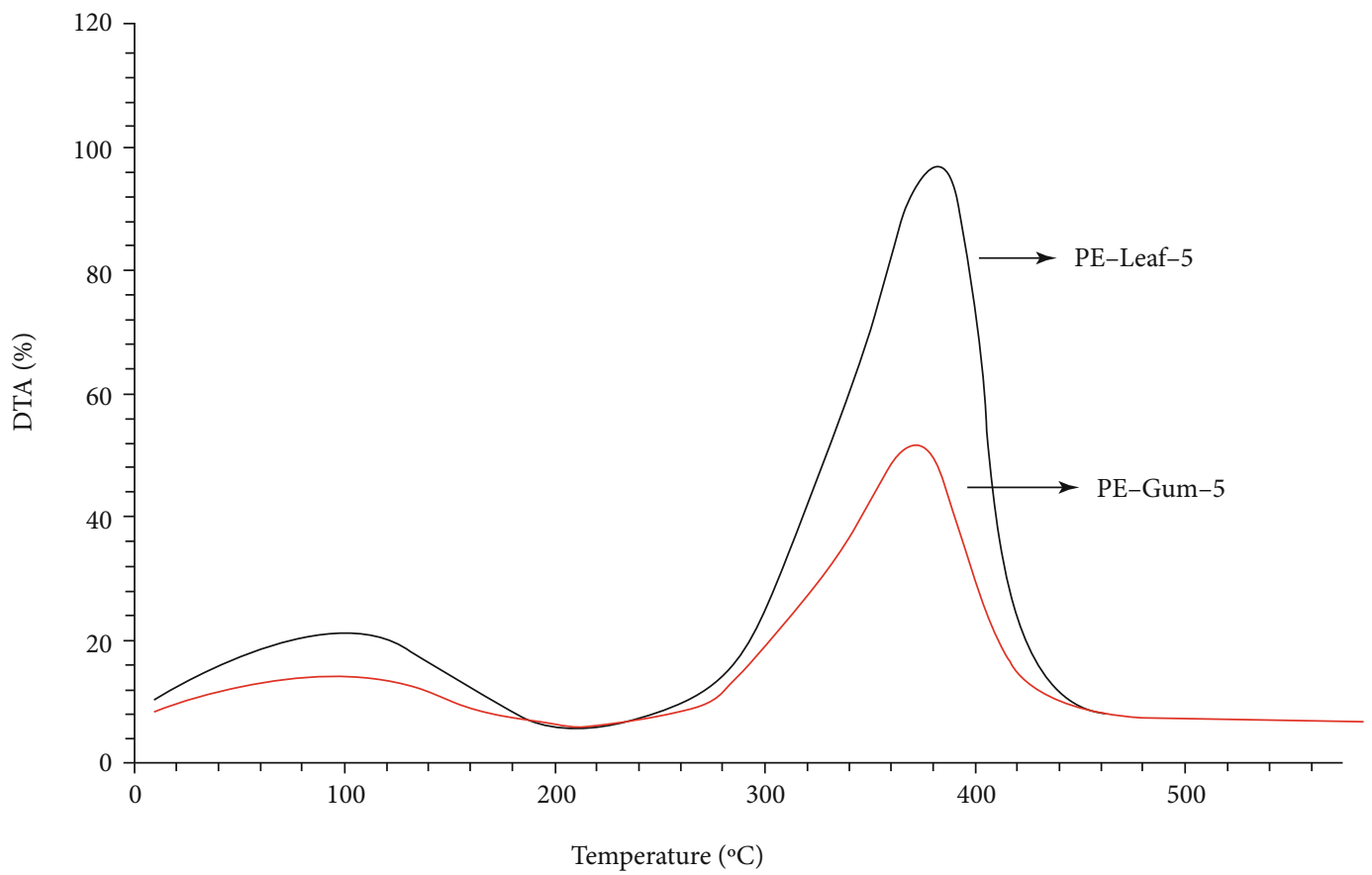

(b)

FIgURE 4: DTA thermograms: (a) pure LDPE film; b) active films.

in the second peak, they were actually considering as the main peak. It is noted that the melting temperature of the films containing the extract was in the range of 240 to $261^{\circ} \mathrm{C}$, which was significantly higher than the melting temperature of the pure LDPE and close to the melting temperature of the leaf and gum extract. These observations indicated an interaction between the extracts with the polyethylene and their miscibility. Increasing in the concentration of the leaf and gum extracts was associated with decreasing and slightly increasing in the melting temperature of the films containing them, respectively.
The position of the endothermic peak in the obtained diagrams was a measure of the melting temperature of the polymer, and the extent of the peaks indicated the content of the polymer or other material in the mixture [42]. Confirming the results of the present study, Chen et al. [34] observed three-stage degradation in the PVA films containing clove oil $(1,3,5,7$, and $9 \% w / w)$. The first stage with $8 \%$ weight loss (temperature from 30 to $180^{\circ} \mathrm{C}$ ) was attributed to the water evaporation and decomposition of clove oil. The second stage with $60 \%$ degradation $\left(180\right.$ to $\left.350^{\circ} \mathrm{C}\right)$ was related to the decomposition of PVA side chains, and 


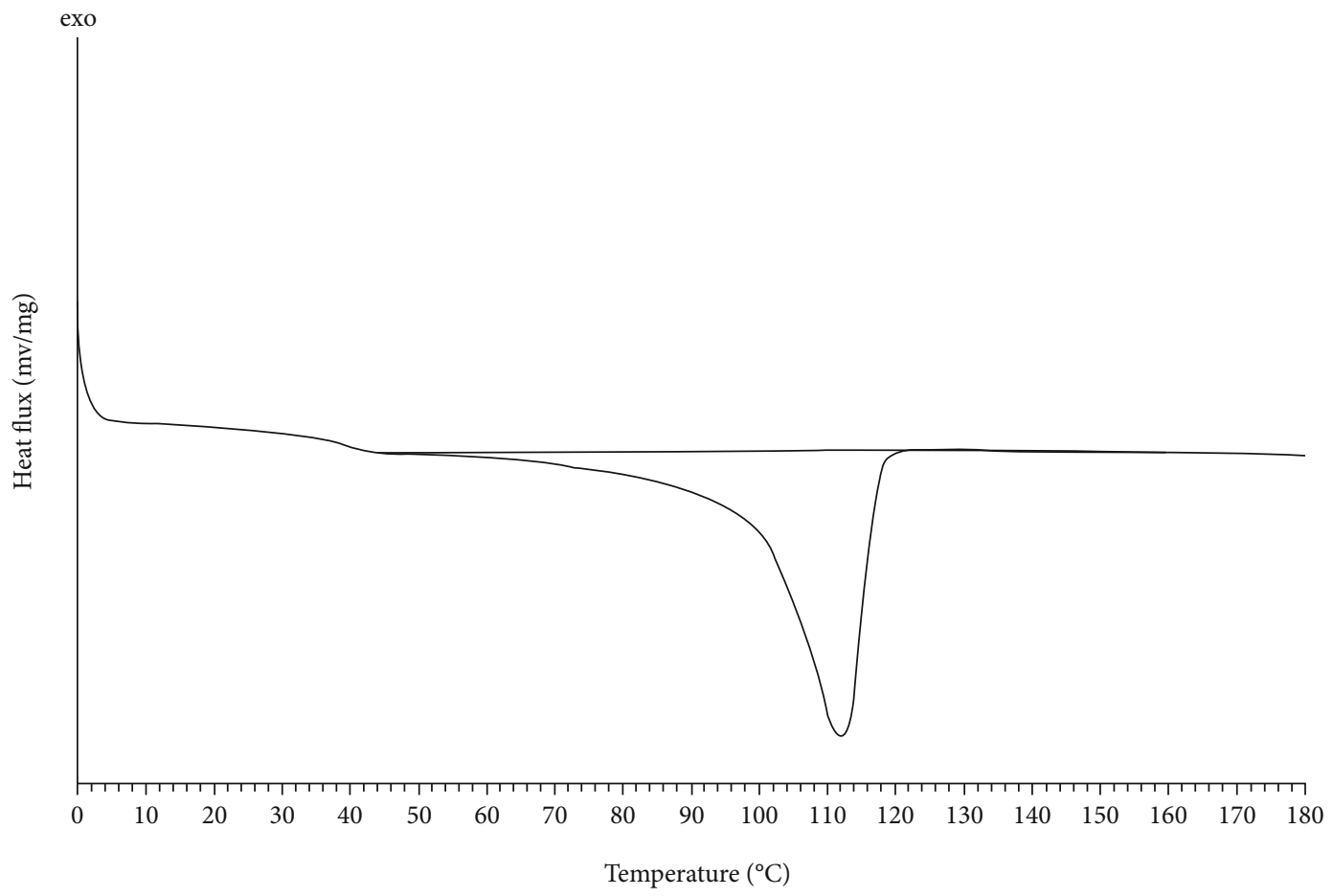

(a)

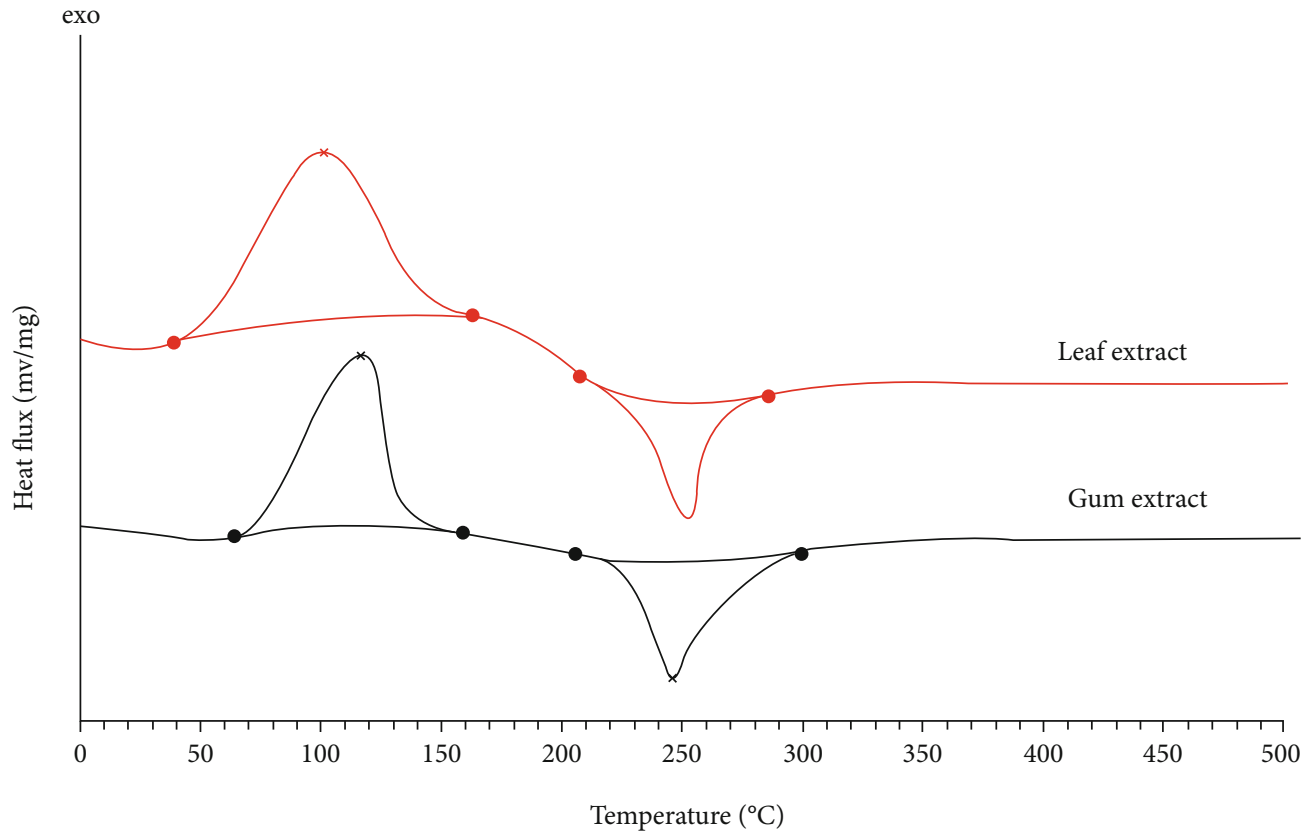

(b)

FIGURE 5: DSC thermograms: (a) polyethylene film; (b) leaf and gum extracts.

the third stage of the degradation (temperature from 350 to $520^{\circ} \mathrm{C}$ ) was related to the decomposition of the main PVA chain.

The results showed a very high enthalpy of the leaf and gum extracts while adding them to the LDPE, which reduced the enthalpy significantly, but the enthalpy of these films was still higher than that of pure LDPE. This implies the existence of heat-resistant compounds in the leaf and gum extracts.
Increasing in the concentration of extracts in the film, increased the enthalpy. The results showed that the melting temperature of the blending film was affected by the polymer melting temperature as well as the melting of the added secondary material.

3.9. Antimicrobial Activity. The antimicrobial effects of the PE-Leaf-5 and PE-Gum-5 films on A. niger and S. cerevisiae 


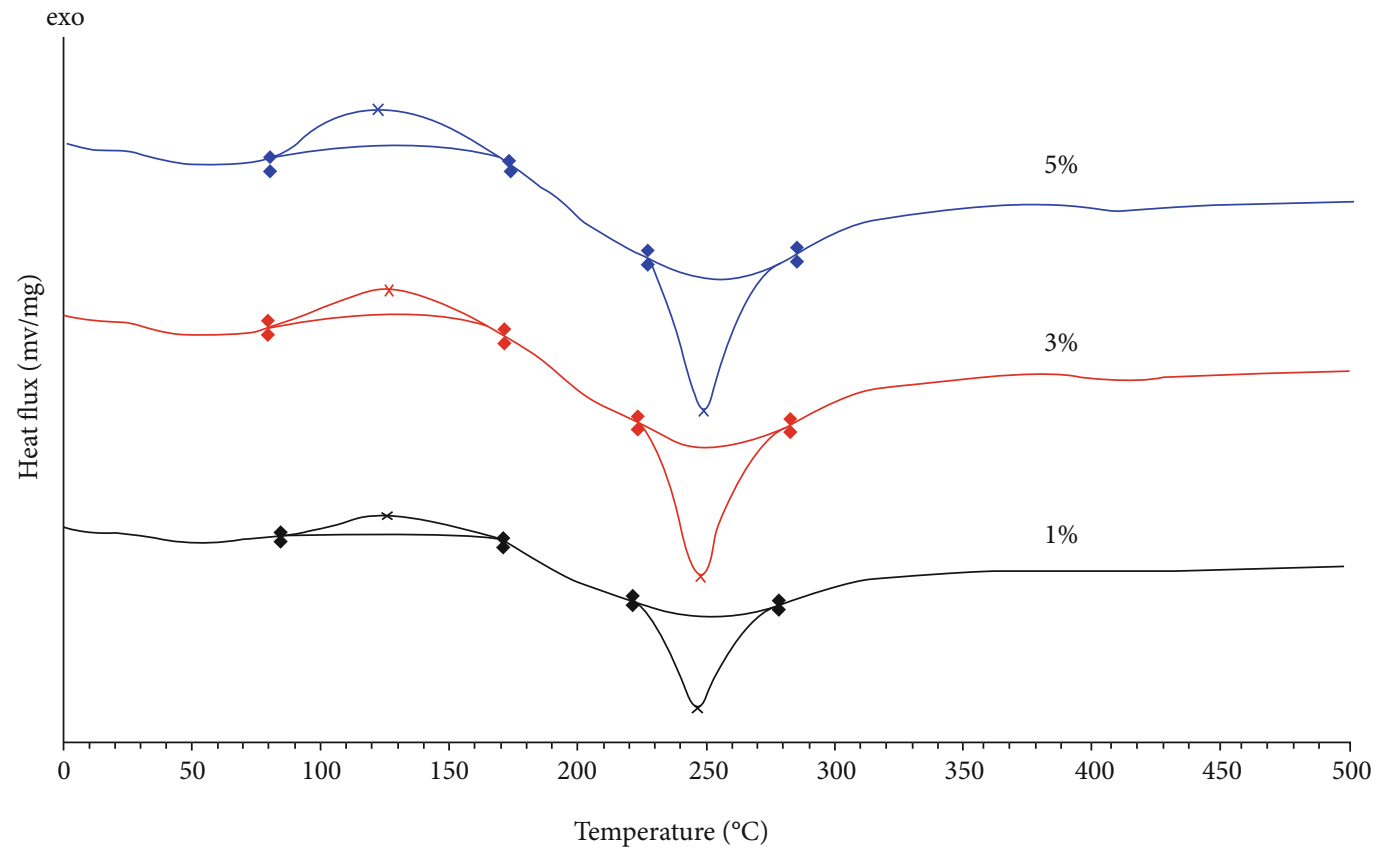

(a)

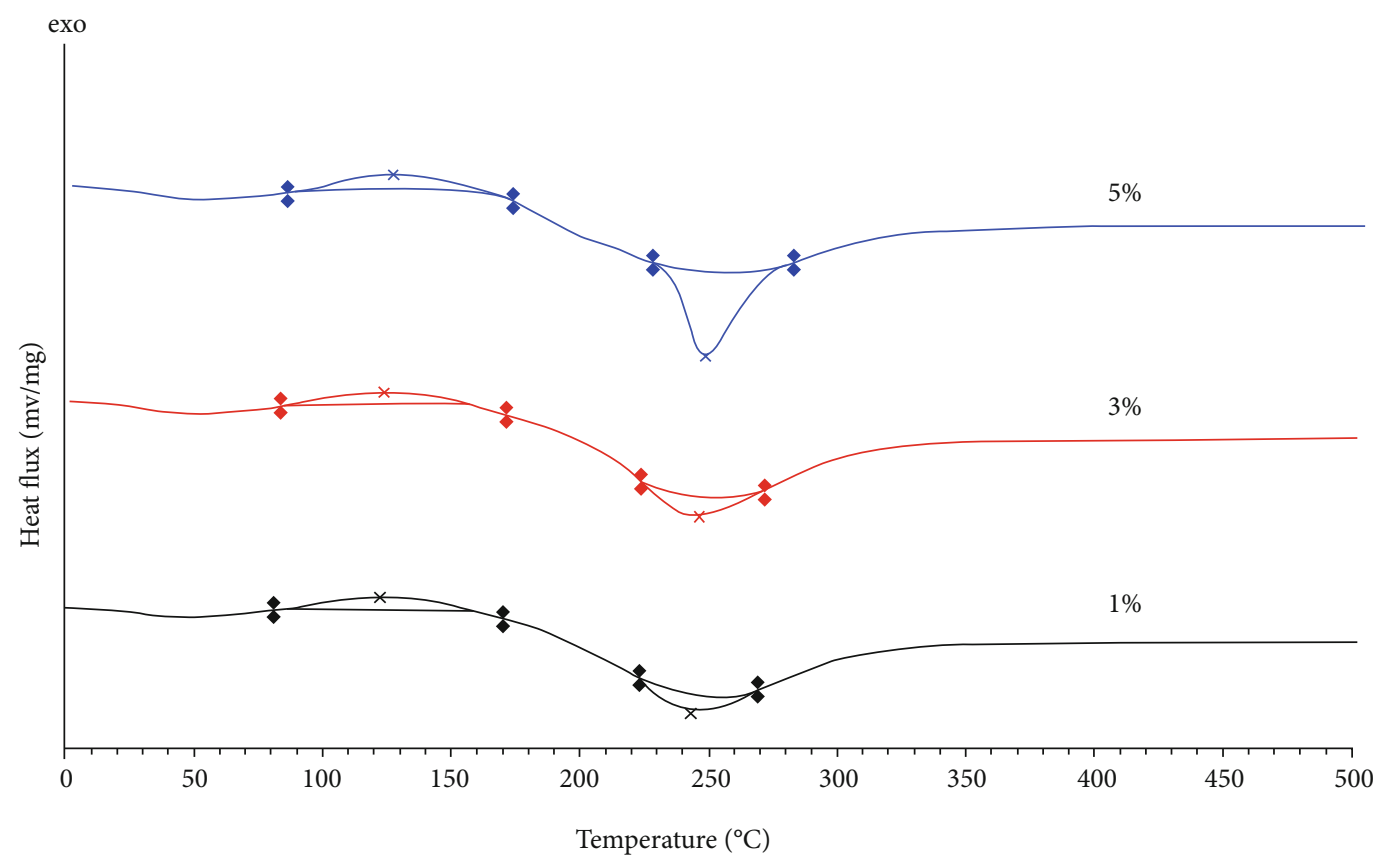

(b)

FIGURE 6: DSC thermograms of polyethylene films containing 1, 3, and 5\%: (a) leaf extract; b) gum extract.

within 14 days compared to the pure LDPE film is shown in Figure 7. The antimicrobial activity of the films containing different concentrations of the leaf extract and gum on the activity of A. niger in 14 days compared to control was shown in Figure $7(\mathrm{a})$. The pure LDPE film did not show any significant inhibitory effect on $A$. niger growth within 14 days $(P>0.05)$. As shown in Figure 7(a), a significant inhibitory effect on the growth of $A$. niger was observed in the PE-Leaf-5 films after 7 days (1.37 logarithmic cycles compared to the first day), and the growth of A.niger inhibited more noticeably (3.23 logarithmic cycles reduction) after 14 days. In the presence of PEGum-5, after 7 days 0.98 logarithmic cycles and after 14 days 3.72 logarithmic cycles decrease was observed in $A$. niger growth compared to the first day. It seems that the antimicrobial effect of films containing leaf and gum extracts on $A$. niger had no significant difference with each other.

The antimicrobial effect of active films comparing to the LDPE film on S. cerevisiae during 14 days is shown in 
TABLE 6: Thermal properties (starting, peak, and end points $\left({ }^{\circ} \mathrm{C}\right)$ ) and enthalpy $(\mathrm{mJ} / \mathrm{mg})$ of leaf and gum extracts and films containing them.

\begin{tabular}{|c|c|c|c|c|c|c|c|c|c|}
\hline \multirow[t]{2}{*}{ Sample } & \multirow[t]{2}{*}{ Concentration (\%) } & \multicolumn{4}{|c|}{ Peak 1} & \multicolumn{4}{|c|}{ Peak 2} \\
\hline & & $\mathrm{T}_{0}$ & $\mathrm{~T}_{\mathrm{p}}$ & $\mathrm{T}_{\mathrm{e}}$ & $\Delta \mathrm{H}$ & $\mathrm{T}_{0}$ & $\mathrm{~T}_{\mathrm{p}}$ & $\mathrm{T}_{\mathrm{e}}$ & $\Delta \mathrm{H}$ \\
\hline Gum extract & - & 61.4 & 111.0 & 160.2 & 869.5 & 207.4 & 248.0 & 300.0 & 728.2 \\
\hline Leaf extract & - & 38.0 & 99.9 & 160.3 & 925.1 & 205.0 & 250.0 & 289.1 & 649.3 \\
\hline \multirow[t]{2}{*}{ Polyethylene film } & - & 37.9 & 42.8 & 45.8 & 1.7 & 100.0 & 111.9 & 117.9 & 88.5 \\
\hline & 1 & 79.2 & 118.8 & 165.3 & 167.0 & 218.9 & 247.9 & 279.4 & 477.5 \\
\hline \multirow[t]{3}{*}{ PE-Leaf } & 3 & 74.7 & 119.1 & 168.6 & 190.5 & 219.6 & 246.4 & 292.3 & 496.8 \\
\hline & 5 & 66.6 & 110.6 & 167.9 & 213.3 & 221.1 & 245.1 & 282.1 & 509.8 \\
\hline & 1 & 79.9 & 119.6 & 169.2 & 122.8 & 220.2 & 241.3 & 269.1 & 118.2 \\
\hline \multirow[t]{2}{*}{ PE-Gum } & 3 & 80.3 & 120.0 & 169.3 & 150.4 & 220.0 & 242.9 & 270.8 & 149.3 \\
\hline & 5 & 80.3 & 119.5 & 169.4 & 159.6 & 220.8 & 243.9 & 279.7 & 388.9 \\
\hline
\end{tabular}

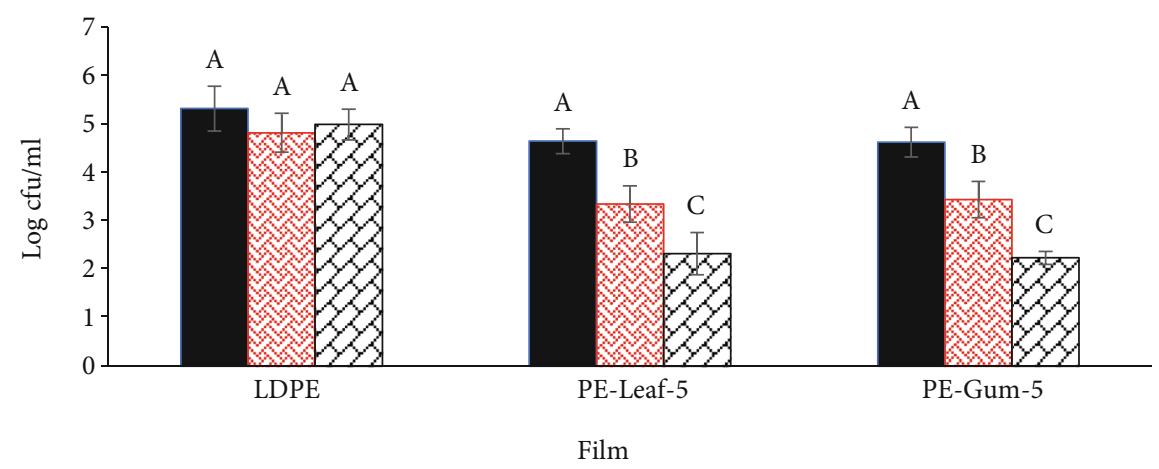

$$
\begin{aligned}
& \mathbf{1} \text { day } \\
& 7 \text { day } \\
& \square 14 \text { day }
\end{aligned}
$$

(a)

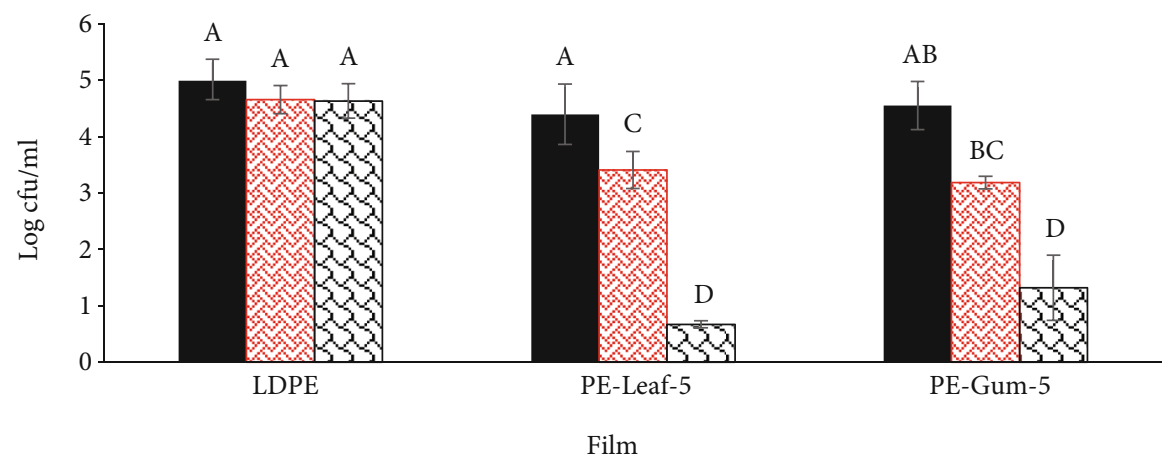

(b)

FIGURE 7: Antimicrobial effect of active films containing on (a) A. niger and (b) S. cerevisiae during 14 days at $25^{\circ} \mathrm{C}$. Error bars show standard deviation (SD). Nonsimilar letters on each column indicate a significant difference according to Tukey's test $(P<0.05)$.

Figure 7(b). As is obvious, the trend of the effect of the PELeaf-5 films on S. cerevisiae was similar to the effect of these films on $A$. niger. The antimicrobial effect of the PE-Leaf-5 resulted in $0.35,1.65$, and 2.68 logarithmic cycles decrease in the $1^{\text {st }}, 7^{\text {th }}$, and $14^{\text {th }}$ days, compared to the initial rate of yeast $\left(10^{5}\right)$, respectively.

The results of the antimicrobial performance of PEGum-5 on S. cerevisiae activity (Figure 7(b)) showed that with increasing the time, the antimicrobial effect of films increased. It can be related to the dissolution and release of antimicrobial compounds from the film into the culture medium containing S. cerevisiae. After 7 days, in the PEGum-5 a significant decrease (1.19 logarithmic cycles, compared to the first day) in the growth of $S$. cerevisiae was seen $(P<0.05)$. At the end of 14 days, a logarithmic cycle of decrease of 2.39 was observed in the presence of PE-Gum-5 compared to the first day. The results of Jafarzadeh et al. [39] reported that active semolina films containing zinc oxide are primarily effective on the fungi (A. niger) followed by yeasts (Candida albicans) and bacteria (S. aureus and E. coli) 
were effective, and the increasing in the concentration of the zinc oxide increased the antimicrobial effect, which was confirmed by the results of this study. The antimicrobial effects of the PE-Leaf and PE-Gum films can be attributed to the presence of antimicrobial compounds in the Ferula leaf and gum extracts such as $\alpha$-pinene and ferulic acid, umbelliprenin, sulfur compounds, which was mentioned formerly. The bactericidal effect of soy protein isolate films containing Cortex Phellodendron extract was attributed to the release of alkaloids resulted in the degradation of the bacterial cell surface structure, which led to the release of $\mathrm{Ca}^{2+}$ and $\mathrm{K}^{+}$from the cell and its effects on the enzymes, DNA replication, RNA transcription, and protein biosynthesis [33].

\section{Conclusion}

The present study aimed to investigate the properties of the LDPE active films containing different concentrations of Ferula leaf and gum extracts. The results showed that the addition of the extracts caused the disruption of the LDPE polymer matrix and affected its mechanical, thermal, optical, and microstructural properties. Increasing the extract concentration in the films decreased their elongation and tensile strength. The FTIR results also showed the partial interaction between the extract compounds and the polymer matrix. The addition of the extracts to the polymer matrix increased the transmission rate of water vapor and oxygen. The results also confirmed the good antifungal efficiency of films due to the mild release of the bioactive component of $\mathrm{F}$. asafoetida. However, the mild release is desirable for the foods that gradually decayed. In general, the results showed that the LDPEbased films containing the leaf and gum extracts have a promising potential as a bioactive packaging material and can be used to improve the food safety and quality while has a good mechanical, thermal, and barrier properties.

\section{Data Availability}

The permitted part of the data used to support the findings of this study is available from the corresponding author upon request.

\section{Conflicts of Interest}

The authors declare that they have no conflicts of interest.

\section{Acknowledgments}

The authors acknowledge the Iran National Science Foundation (INSF) for financial support of this work (grant no. 9411113).

\section{References}

[1] M. Carocho, P. Morales, and I. C. F. R. Ferreira, "Natural food additives: Quo vadis?," Trends in Food Science \& Technology, vol. 45, no. 2, pp. 284-295, 2015.

[2] G. L. Robertson, Food Packaging: Principles and Practice. 755 (3rd ed.)., CRC Press (2012) Taylor \& Francis Group, Boca Rotan, 2012.
[3] J. Zia, U. C. Paul, J. A. Heredia-Guerrero, A. Athanassiou, and D. Fragouli, "Low-density polyethylene/curcumin melt extruded composites with enhanced water vapor barrier and antioxidant properties for active food packaging," Polymer, vol. 175, pp. 137-145, 2019.

[4] S.-Y. Sung, L. T. Sin, T.-T. Tee et al., "Antimicrobial agents for food packaging applications," Trends in Food Science \& Technology, vol. 33, no. 2, pp. 110-123, 2013.

[5] J.-H. Li, J. Miao, J.-L. Wu, S.-F. Chen, and Q.-Q. Zhang, "Preparation and characterization of active gelatin-based films incorporated with natural antioxidants," Food Hydrocolloids, vol. 37, pp. 166-173, 2014.

[6] M. del Mar Castro López, S. D. García, A. A. Pernas, J. M. L. Vilariño, and M. V. G. Rodríguez, "Effect of PPG-PEG-PPG on the Tocopherol-Controlled Release from Films Intended for Food-Packaging Applications," Journal of Agricultural and Food Chemistry, vol. 60, no. 33, pp. 8163-8170, 2012.

[7] J. Rosen-Kligvasser, R. Y. Suckeveriene, R. Tchoudakov, and M. Narkis, "LLDPE films containing monoester of oleic acid grafted to silica particles as durable antifog additives," Polymers for Advanced Technologies, vol. 28, no. 8, pp. 931-939, 2017.

[8] L. de Dicastillo et al., "Development of New Antioxidant Active Packaging Films Based on Ethylene Vinyl Alcohol Copolymer (EVOH) and Green Tea Extract," Journal of Agriculture and Food Chemistry, vol. 59, pp. 7832-7840, 2011.

[9] K. Wattananawinrat, P. Threepopnatkul, and C. Kulsetthanchalee, "Morphological and Thermal Properties of LDPE/EVA Blended Films and Development of Antimicrobial Activity in Food Packaging Film," Energy Procedia, vol. 56, pp. 1-9, 2014.

[10] C. J. Kerbs, Ecological Methodology, Harper Collins Publishers, New York, USA, 1989.

[11] M. Fatehi, F. Farifteh, and Z. Fatehi-Hassanabad, "Antispasmodic and hypotensive effects of Ferula asafoetida gum extract," Journal of Ethnopharmacology, vol. 91, no. 2-3, pp. 321-324, 2004.

[12] D. Eigner and D. Scholz, "Das Zauberbüchlein der Gyani Dolma," Pharmazie in Unserer Zeit, vol. 19, no. 4, pp. 141$152,1990$.

[13] N. S. Mohammad, A. A. Dehpour, M. A. Ebrahimzadeh, and N. S. Fazel, "Antioxidant activity of the methanol extract of Ferula assafoetida and its essential oil composition," Grasas y Aceites, vol. 60, no. 4, pp. 405-412, 2009.

[14] A. Amalraj and S. Gopi, "Biological activities and medicinal properties of Asafoetida: A review," Journal of Traditional and Complementary Medicine, vol. 7, no. 3, pp. 347-359, 2017.

[15] M. Iranshahy and M. Iranshahi, "Traditional uses, phytochemistry and pharmacology of asafoetida (Ferula assafoetida oleo-gum-resin)-A review," Journal of Ethnopharmacology, vol. 134, no. 1, pp. 1-10, 2011.

[16] G. Takeoka, "Volatile Constituents of Asafoetida," in ACS Symposium Series, G. R. Takeoka, M. Guntert, and K.-H. Engel, Eds., pp. 33-44, American Chemical Society, Washington, DC, 2001.

[17] H. Delavar, M. J. Saharkhiz, and N. Kazerani, "Essential oil analysis and phytotoxic activity of ferula assa-foetida L," Iranian Journal of Medicinal and Aromatic Plants, vol. 3, no. 65, pp. 433-444, 2014.

[18] S. D. Patil, S. Shinde, P. Kandpile, and A. S. Jain, "Evaluation of antimicrobial activity of asafetida," International Journal of 
Pharmaceutical Sciences and Research, vol. 6, no. 2, pp. 722727, 2015.

[19] M. M. Fani, A. Bazargani, M. A. Farboodniay Jahromi, Z. Hasanpour, K. Zamani, and E. Yousefi Manesh, "An in Vitro Study on the Antibacterial Effect of Ferula AssaFoetida L. and Quercus Infectoria Olivier Extracts on Streptococcus Mutans and Streptococcus Sanguis," Avicenna Journal of Dental Research, vol. 7, no. 1, 2015.

[20] V. Shrivastava, U. Bhardwaj, V. Sharma, N. Mahajan, V. Sharma, and G. Shrivastava, "Antimicrobial activities of Asafoetida resin extracts (a potential Indian spice)," Journal of Pharmacy Research, vol. 5, no. 10, pp. 5022-5024, 2012.

[21] L. R. Braga, L. M. Pérez, M. d. V. Soazo, and F. Machado, "Evaluation of the antimicrobial, antioxidant and physicochemical properties of Poly(Vinyl chloride) films containing quercetin and silver nanoparticles," $L W T$, vol. 101, pp. 491498, 2019.

[22] S. Hajinezhad, B. M. Razavizadeh, and R. Niazmand, "Study of antimicrobial and physicochemical properties of LDPE/propolis extruded films," Polymer Bulletin, 2019, In press.

[23] W. Liu, Y. J. Wang, and Z. Sun, "Effects of polyethylenegrafted maleic anhydride (PE-g- MA) on thermal properties, morphology, and tensile properties of low-density polyethylene (LDPE) and corn starch blends," Journal of Applied Polymer Science, vol. 88, no. 13, pp. 2904-2911, 2003.

[24] N. M. Vicentini, N. Dupuy, M. Leitzelman, M. P. Cereda, and P. J. A. Sobral, "Prediction of Cassava Starch Edible Film Properties by Chemometric Analysis of Infrared Spectra," Spectroscopy Letters, vol. 38, no. 6, pp. 749-767, 2007.

[25] M. M. Sangatash, R. Niazmand, M. S. Jamab, and A. S. Modaressi, "Development of antioxidant active films containing sodium ascorbate (SA) and ethylene vinyl alcohol (EVOH) to extend the shelf life of peanut," Journal of Food Science and Technology, vol. 53, no. 4, pp. 1766-1783, 2016.

[26] S. Saeidy, A. Nasirpour, J. Keramat et al., "Structural characterization and thermal behavior of a gum extracted from _Ferula assa foetida_ L.", Carbohydrate Polymers, vol. 181, no. 181, pp. 426-432, 2018.

[27] M. Mulla, J. Ahmed, H. Al-Attar, E. Castro-Aguirre, Y. A. Arfat, and R. Auras, "Antimicrobial efficacy of clove essential oil infused into chemically modified LLDPE film for chicken meat packaging," Food Control, vol. 73, pp. 663-671, 2017.

[28] C. Pastor, L. Sánchez-González, M. Cháfer, A. Chiralt, and C. González-Martínez, "Physical and antifungal properties of hydroxypropylmethylcellulose based films containing propolis as affected by moisture content," Carbohydrate Polymers, vol. 82, no. 4, pp. 1174-1183, 2010.

[29] A. P. Martínez-Camacho, M. O. Cortez-Rocha, A. Z. Graciano-Verdugo et al., "Extruded films of blended chitosan, low density polyethylene and ethylene acrylic acid," Carbohydrate Polymers, vol. 91, no. 2, pp. 666-674, 2013.

[30] J. H. Zhang, H. L. Sun, S. Y. Chen, L. Zeng, and T. T. Wang, "Anti-fungal activity, mechanism studies on $\alpha$-phellandrene and nonanal against penicillium cyclopium," Botanical Studies, vol. 58, no. 1, p. 13, 2017.

[31] L. N. Remedio, J. W. Silva dos Santos, V. B. Vieira Maciel, C. M. P. Yoshida, and R. Aparecida de Carvalho, "Characterization of active chitosan films as a vehicle of potassium sorbate or nisin antimicrobial agents," Food Hydrocolloids, vol. 87, pp. 830-838, 2019.
[32] Y. Ma, L. Li, and Y. Wang, "Development of antimicrobial active film containing CINnamaldehyde and its application to snakehead (Ophiocephalus argus ) fish," Journal of Food Process Engineering, vol. 40, no. 5, p. e12554, 2017.

[33] S. Liang and L. Wang, "A Natural Antibacterial-Antioxidant Film from Soy Protein Isolate Incorporated with Cortex Phellodendron Extract," Polymers, vol. 10, no. 1, p. 71, 2018.

[34] C. Chen, Z. Xu, Y. Ma et al., "Properties, vapour-phase antimicrobial and antioxidant activities of active poly (vinyl alcohol) packaging films incorporated with clove oil," Food Control, vol. 88, pp. 105-112, 2018.

[35] M. R. Galdi and L. Incarnato, "Influence of composition on structure and barrier properties of active PET films for food packaging applications," Packaging Technology and Science, vol. 24, no. 2, pp. 89-102, 2011.

[36] M. Ramos, A. Jimenez, M. Peltzer, and M. C. Garrigos, "Characterization and antimicrobial activity studies of polypropylene films with carvacrol and thymol for active packaging," Journal of Food Engineering, vol. 109, no. 3, pp. 513-519, 2012.

[37] L. Cui, L.-p. Xu, F.-C. Tsai, P. Zhu, T. Jiang, and J.-t. Yeh, “Oxygen depletion properties of glucose-grafted polyethylene resins filled with sodium ascorbate/modified iron compounds," Journal of Polymer Research, vol. 18, no. 6, pp. 1301-1313, 2011.

[38] Z. A. Maryam Adilah, B. Jamilah, and Z. A. Nur Hanani, "Functional and antioxidant properties of protein-based films incorporated with mango kernel extract for active packaging," Food Hydrocolloids, vol. 74, pp. 207-218, 2018.

[39] S. Jafarzadeh, J. W. Rhim, A. K. Alias, F. Ariffin, and S. Mahmud, "Application of antimicrobial active packaging film made of semolina flour, nano zinc oxide and nanokaolin to maintain the quality of low-moisture mozzarella cheese during low-temperature storage," Journal of the Science of Food and Agriculture, vol. 99, no. 6, pp. 2716-2725, 2019.

[40] A. W. Coats and J. P. Redfern, “Thermogravimetric analysis. A review," The Analyst, vol. 88, no. 1053, p. 906, 1963.

[41] M. P. Arrieta, M. d. M. Castro-López, E. Rayón et al., "Plasticized Poly(lactic acid)-Poly(hydroxybutyrate) (PLA-PHB) Blends Incorporated with Catechin Intended for Active Food-Packaging Applications," Journal of Agricultural and Food Chemistry, vol. 62, no. 41, pp. 10170-10180, 2014.

[42] J.-Z. Liang, "The elastic behaviour during capillary extrusion of LDPE/LLDPE blend melts," Polymer Testing, vol. 21, no. 1, pp. 69-74, 2002. 